\title{
Contributions of cerebellar event-based temporal processing and preparatory function to speech perception
}

Citation for published version (APA):

Schwartze, M., \& Kotz, S. A. (2016). Contributions of cerebellar event-based temporal processing and preparatory function to speech perception. Brain and Language, 161, 28-32.

https://doi.org/10.1016/j.bandl.2015.08.005

Document status and date:

Published: 01/10/2016

DOI:

10.1016/j.bandl.2015.08.005

Document Version:

Publisher's PDF, also known as Version of record

\section{Document license:}

Taverne

\section{Please check the document version of this publication:}

- A submitted manuscript is the version of the article upon submission and before peer-review. There can be important differences between the submitted version and the official published version of record.

People interested in the research are advised to contact the author for the final version of the publication, or visit the DOI to the publisher's website.

- The final author version and the galley proof are versions of the publication after peer review.

- The final published version features the final layout of the paper including the volume, issue and page numbers.

Link to publication

\footnotetext{
General rights rights.

- You may freely distribute the URL identifying the publication in the public portal. please follow below link for the End User Agreement:

www.umlib.nl/taverne-license

Take down policy

If you believe that this document breaches copyright please contact us at:

repository@maastrichtuniversity.nl

providing details and we will investigate your claim.
}

Copyright and moral rights for the publications made accessible in the public portal are retained by the authors and/or other copyright owners and it is a condition of accessing publications that users recognise and abide by the legal requirements associated with these

- Users may download and print one copy of any publication from the public portal for the purpose of private study or research.

- You may not further distribute the material or use it for any profit-making activity or commercial gain

If the publication is distributed under the terms of Article $25 \mathrm{fa}$ of the Dutch Copyright Act, indicated by the "Taverne" license above, 


\title{
Contributions of cerebellar event-based temporal processing and preparatory function to speech perception
}

\author{
Michael Schwartze ${ }^{1}$, Sonja A. Kotz ${ }^{* 1}$ \\ School of Psychological Sciences, University of Manchester, Manchester, United Kingdom \\ Dept. of Neuropsychology, Max Planck Institute for Human Cognitive and Brain Sciences, Leipzig, Germany \\ Faculty of Psychology and Neuroscience, Dept. of Neuropsychology and Psychopharmacology, Maastricht University, Maastricht, The Netherlands
}

\section{A R T I C L E I N F O}

\section{Article history:}

Received 19 January 2015

Revised 23 June 2015

Accepted 19 August 2015

Available online 9 September 2015

\section{Keywords:}

Cerebellum

Temporal processing

Language

Audition

Prediction

\begin{abstract}
A B S T R A C T
The role of the cerebellum in the anatomical and functional architecture of the brain is a matter of ongoing debate. We propose that cerebellar temporal processing contributes to speech perception on a number of accounts: temporally precise cerebellar encoding and rapid transmission of an event-based representation of the temporal structure of the speech signal serves to prepare areas in the cerebral cortex for the subsequent perceptual integration of sensory information. As speech dynamically evolves in time this fundamental preparatory function may extend its scope to the predictive allocation of attention in time and supports the fine-tuning of temporally specific models of the environment. In this framework, an oscillatory account considering a range of frequencies may best serve the linking of the temporal and speech processing systems. Lastly, the concerted action of these processes may not only advance predictive adaptation to basic auditory dynamics but optimize the perceptual integration of speech.
\end{abstract}

(c) 2015 Elsevier Inc. All rights reserved.

\section{Introduction}

Recent interest and substantial progress in our understanding of cerebellar contributions to neurocognitive processes beyond the motor domain has been summarized in a comprehensive body of work (Baumann et al., 2014; Koziol et al., 2014; Manto et al., 2012; Mariën et al., 2014). It is important to note that a broad range of functions ascribed to the cerebellum is paralleled by increasingly detailed knowledge about its structural connectivity, which, in turn, allows speculation about complex cerebellocortical and cerebello-subcortical interactions (Akkal, Dum, \& Stick, 2007; Bernard et al., 2013; Bostan, Dum, \& Strick, 2013; Buckner, Krienen, Castellanos, Diaz, \& Yeo, 2011; Chen, Fremont, Arteaga-Bracho, \& Khodakhah, 2014; Strick, Dum, \& Fiez, 2009). However, these empirical findings and theoretical frameworks tend to compete against a prevailing notion of the cerebellum as a genuine motor structure. In this aspect, cerebellar research is reminiscent of research in the language domain with a strong dichotomy of Broca's and Wernicke's area and their association with language production and perception. However, cerebellar

\footnotetext{
* Corresponding author at: Faculty of Psychology and Neuroscience, Dept. of Neuropsychology and Psychopharmacology, P.O. Box 616, 6200 MD Maastricht, The Netherlands.

E-mail address: sonja.kotz@maastrichtuniversity.nl (S.A. Kotz).

1 The authors contributed equally to this work.
}

activity is found in the absence of movement, for example, in response to auditory stimulation including spoken language (Ackermann, 2008; Ackermann \& Hertrich, 2000; Lockwood et al., 1999; Petacchi, Laird, Fox, \& Bower, 2005). Accordingly, cerebellar contributions to language in general, and speech in particular, have been one of the major foci in the recent scientific discussion (for reviews see Mariën et al., 2014; Murdoch, 2010).

In the following, we will outline a proposal along these lines and discuss how specific contributions of the cerebellum regarding temporal and preparatory function may integrate into our understanding of speech perception. This proposal builds on the notion that the classical distinction of linguistic competence ("knowledge of a language") and linguistic performance ("actual use of a language"; Chomsky, 1965) is fundamental to our understanding of the cerebellar contributions to speech perception. Successful linguistic performance needs to be conceived as our capacity to use linguistic rules and constraints but requires, at the same time, that we cope with contextual variation, errors, memory limitations, and shifts of attention in concrete communicative settings (see for initial thoughts Chomsky, 1965). In line with such thinking we suggest that the cerebellum contributes to all of the latter aspects in speech perception. In particular, we will focus on two aspects: (i) the role of the cerebellum in temporal processing and "the preparation in advance of sensory events" (Courchesne \& Allen, 1997; Ivry \& Schlerf, 2008) and (ii) cerebellar connections to temporal and frontal cortices and how these connections may be reflected 
by oscillatory activity. We acknowledge that a comprehensive account of cerebellar contributions to speech and language function will ultimately have to consider cerebellar subregions and their connections to temporo-parietal areas. However, we conceive the current opinion as a thought experiment that motivates why considering the contribution of these two aspects is essential in speech perception, thereby extending our earlier work on nonspeech and speech specific auditory processing (Kotz \& Schwartze, 2010; Schwartze \& Kotz, 2013; Schwartze, Tavano, Schröger, \& Kotz, 2012).

\section{Dynamics in speech and speech perception}

Speech serves the communication of meaning. This purpose is achieved by means of (neuro-) physiological processes that engage in the production and perception of speech, one of the most complex time-varying signals. In speech perception, the auditory system integrates sound features over multiple time-scales, ranging from tenths of a second ( $\mathrm{a}$ few $\mathrm{Hz}$ ) to milliseconds $(\mathrm{kHz})$ (Rosen, 1992; Shamma, 2003). The dynamic and fleeting nature of the signal implies that speech perception involves some form of synchronization between a speaker and the decoding capacity of a listener (Greenberg, Carvey, Hitchcock, \& Chang, 2003). Even though the speech signal is complex and our cognitive resources are limited, speech perception is a remarkably robust phenomenon. Consequently, speech perception must make opportunistic use of all types of information that are conveyed by the signal, including temporal information. In other words, the temporal structure of the signal may constitute a relevant source of information in its own right. Accordingly, domain-general dedicated processes specialized in the processing of temporal information may optimize general auditory processing and speech perception. A listener's ability to make use of the temporal structure of a dynamic signal may hence, in part, be responsible for qualitative differences in speech perception.

\section{Cerebellar temporal processing and preparatory function}

The cerebellum is among the brain regions that are most consistently associated with dedicated temporal processing, apart from the basal ganglia, the supplementary motor area, and prefrontal areas (Buhusi \& Meck, 2005; Coull, Cheng, \& Meck, 2011; Ivry \& Schlerf, 2008; Wiener, Turkeltaub, \& Coslett, 2010). The notion of dedicated temporal processing essentially implies a modular clock-like system that is specialized for representing temporal inter-event-relationships (Ivry \& Schlerf, 2008). Accordingly, the cerebellar timing hypothesis suggests that the cerebellum establishes a precise representation of the temporal relation of salient events in the subsecond range (Ivry, 1996; Ivry \& Schlerf, 2008; Spencer \& Ivry, 2013; Spencer, Zelaznik, Diedrichsen, \& Ivry, 2003). This event-based, short-range, and potentially also automatic cerebellar temporal processing system works in parallel with another dedicated system. This second system builds on oscillatory mechanisms in cortico-striato-thalamo-cortical circuits and performs interval-based, longer-range, and attention-dependent temporal processing (Buhusi \& Meck, 2005).

Next to dedicated event-based temporal processing, the cerebellum has been associated with the complex interplay of attention, prediction, and preparation (Courchesne \& Allen, 1997). The cerebellar preparatory function has been described as a domain-general process, in which the cerebellum predicts the internal conditions that are required for a particular mental or motor operation (including sensory, memory, attention, and speech-related operations) and prepares these conditions for operations in the respective neural systems (Courchesne \& Allen, 1997). Critically, this preparatory function is conceived as a dynamic process of constant adaptation to internal and external variation, which entails rapid, effortless, and accurate shifting of attention (Courchesne \& Allen, 1997). Regarding attention, a conceptually similar perspective has been proposed in the dynamic attending theory (Large \& Jones, 1999). According to this theory, inevitable fluctuations of attention are susceptible to the temporal structure of dynamic stimulation. A synchronized stimulus-driven attending mode may be established via the entrainment of adaptive neural "attention" oscillations to the temporal structure of the input, which may, in turn, prepare the organism for the perceptual integration of salient events.

Direct links between the proposed roles of the cerebellum in dedicated temporal processing, preparatory function, and the efficient allocation of attention in time may factor into a more general cerebellar role in guiding behavior that involves real-time prediction (Manto et al., 2012). An adequately precise representation of the temporal structure of successive events generated by the cerebellum and transmitted to cortical target areas via the thalamus may promote temporally specific predictions about the future course of events and allow more efficient preparation for subsequent "information acquisition and analysis" (e.g., by optimal positioning of sensory receptors, modulation of cerebral blood flow, enhanced neural signal-to-noise ratio and responsiveness in target areas including the thalamus; Courchesne \& Allen, 1997). However, in the context of speech perception, a number of immediate questions arise from this proposal such as: Which type(s) of "speech events" may trigger dedicated cerebellar temporal processing? How does auditory information reach the cerebellum in the first place, and where does it go from there? What is known about oscillatory activity at the level of the cerebellum and how may this activity relate to the expanding literature on the role of cortical oscillations in dynamic attending and speech perception?

\section{Auditory events and oscillatory dynamics}

To approach these questions, it seems necessary to detail the notion of "event-based temporal structure." Conceptually speaking, events may be conceived as arising from perceived changes in sensory input. Events thus stand in opposition to duration, i.e., the absence of change. Sensory systems, and the auditory system in particular, respond to signal properties that change as a function of time (Kluender, Coady, \& Kiefte, 2003). The cerebellum receives auditory input not only from temporal areas but also via its connections to the cerebellum-like dorsal cochlear nucleus during early stages of auditory processing (Huang, Liu, \& Huang, 1982; Petacchi et al., 2005). Differential sensitivity of these early processing stages to signal changes (e.g., contrasts in loudness) may result in an adaptively filtered input representation, which preserves particularly salient events such as signal onsets and offsets and steeply rising spectral edges, while it suppresses other information (Schwartze \& Kotz, 2013). This would facilitate the extraction of a discrete (non-linear) event-based representation of temporal structure from the ongoing speech signal. The proposed function of the cerebellum in dedicated temporal processing may thus guarantee temporally precise encoding and rapid transmission of the temporal locus of these events to cortical targets via the thalamus, thereby triggering preparatory processes in these areas. Dualmode response characteristics of thalamic neurons may amplify this cerebellar "clock" signal by firing in a "burst-mode" to evoke more reliable postsynaptic responses effectively instantiating a "wake-up-call" to cortical targets (Sherman, 2001). Once they reach the cortex, the successive signals may guarantee temporal precision and specificity in compliance with the cerebellar preparatory function. Moreover, they may trigger adaptive attention oscillations and/or oscillatory mechanisms implicated in 
attention-dependent temporal processing in cortico-striatothalamo-cortical circuits (Fig. 1). Ultimately, this mechanism may play a role in optimizing the allocation of attention in time and support the perceptual integration or "bridging" of spatially distributed memory representations into a temporally coherent gestalt in frontal areas (Fuster, 1995). In speech perception, the respective memory representations, stored in the middle temporal gyrus and angular gyrus, may be transmitted to these frontal areas via white matter pathways for sentence construction and sentence comprehension, i.e., syntactic and semantic operations (Friederici, 2009; Rilling et al., 2008).

So far, our proposal provides partial answers to the questions about the general characteristics and the flow of auditory information to and from the cerebellar temporal processing system. In the following, we will substantiate this perspective on the basis of converging aspects in cerebellar and cortical oscillatory activity, thereby linking the current proposal to recent discussions about the role of neural oscillations in speech processing.

\section{Oscillatory activity and cerebello-cortical interactions}

Cerebellar encoding of event-based temporal structure and the thalamic amplification of this event-based stimulus representation may be limited to rates between 1 and $10 \mathrm{~Hz}$ (delta-to-theta range), with optimal thalamic responses obtained at about $4 \mathrm{~Hz}$, reminiscent of the natural frequency of mandibular cycles generated during speech production (Giraud et al., 2007; MacNeilage \& Davis, 2001; Sherman \& Guillery, 2006). Electrophysiological studies in rats suggest that auditory evoked responses rapidly decay with stimulation rates $>10 \mathrm{~Hz}$ (Lorenzo, Velluti, Crispino, \& Velluti, 1977), which may, to some extent, reflect the coherence in cerebello-thalamo-frontal networks that is restricted to the theta $(5-10 \mathrm{~Hz})$ frequency range (Watson, Becker, Apps, \& Jones, 2014). The total number of cochlear nucleus cells, which could transmit the adaptively filtered input representation to the cerebellum, is probably small but they may influence a vast number of Purkinje cells if they innervate the cerebellum via mossy fibers (Huang et al., 1982). In turn, afferent mossy fiber activity may be controlled by cerebellar Golgi cells, which display thetafrequency pacemaking behavior but are also optimally sensitive to theta-frequency input, responding with fast, intense, and precise bursts followed by a pause (Solinas et al., 2007). This mechanism may ensure that successive events evoke reliable and temporally distinct clock signals. Critically, Golgi cell activity in response to repetitive theta-frequency stimulation is "anticipated, intensified, and made more precise" (Solinas et al., 2007). The result of this combined effort may be the transmission of a temporally specific and increasingly precise theta-range signal to the thalamus and from there to frontal targets in preparation for the subsequent perceptual integration of memory representations retrieved from temporal areas into a temporally coherent gestalt (see Table 1).

In speech, 1-10 $\mathrm{Hz}$ activity corresponds to a range that overlaps with the syllabic level, and more specifically, with the succession of syllabic nuclei, which may instantiate the successive "signposts," i. e., particularly salient events in the speech signal, which partly determine the overall quality of speech perception (Greenberg, 2006). However, thalamic cells in the classic ascending auditory pathway convey input at considerably higher frequencies. While the potential differential origin of the driving input is diffuse in surface recordings, events in the $1-10 \mathrm{~Hz}$ range and at higher frequencies are associated with different functions in speech perception. Theta oscillations (about 4-8 Hz) may instantiate a "master," which tracks the temporal structure of syllabic input ("theta-sylla ble"), whereas higher frequencies ( $>25 \mathrm{~Hz}$ ) are considered instrumental during memory access (Ghitza, 2012, 2013; Pelle \& Davis,
2012). Furthermore, at this cortical processing level, the basic dissociation of slower and faster range oscillatory activity is also reflected in the differential oscillatory activity obtained from the right (3-6 Hz, the "dominant syllabic rate") and left hemisphere (28-40 Hz, associated with perceptual sensitivity to acoustic correlates of tongue movements produced during articulation that allow discrimination between consonant families; Giraud et al., 2007).

Much less is known about the preceding processing stages of ascending auditory pathways and how they may influence the cortical "outcome." However, as shown in cats, activity of thalamocortical cells in the gamma range is modulated by input from the cerebellum (deZeeuw, Hoebeek, \& Schonewille, 2008; D'Angelo et al., 2009). This mechanism offers a potential explanation for cerebellar influence and interaction with the information flow of the classical auditory pathway at the level of the thalamus. In other words, ongoing cortical activity in the $1-10 \mathrm{~Hz}$ range may in part be determined by the modulation of thalamic activity in response to the event-based representation of temporal structure provided by the cerebellum. In a similar vein, cerebellar activity in speech processing with stimulation rates $>4 \mathrm{~Hz}$, is predominantly rightlateralized and may reflect an interaction of the respective cerebellar and cortical areas, e.g., in right-cerebellar-left-frontal loops and vice versa (Ackermann, Mathiak, \& Riecker, 2007; Ackermann et al., 2001; Callan, Kawato, Parsons, \& Turner, 2007). Activity in higher frequency ranges and induced activity $(10-30 \mathrm{~Hz}$ and $40 \mathrm{~Hz}$, respectively) has been suggested to reflect cerebello-cortical connectivity and frequency-specific coupling (Dalal, Ospinova, Bertrand, \& Jerbi, 2013; Pastor, Vidaurre, Fernández-Seara, Villanueva, \& Friston, 2008). It is important to note that the ongoing oscillatory activity observed in speech perception may reflect both bottom-up and top-down processes mediated via pathways ascending from and descending to the cerebellum. Accordingly, it is unclear if interactions of activity in the theta range and higher frequency activity occur at the level of the cerebellum, the thalamus, or in cortical areas. Several functional implications depend on an answer to this question such as: Is the cerebellar temporal processing system directly involved in the encoding of temporal parameters at the phonemic level (Ackermann et al., 2007) or does the temporal precision of event-based temporal processing at the syllabic level indirectly modulate the quality of phonemic processing in cortical targets (a temporally specific variant of the cerebellar preparatory function)? Yet, oscillatory activity in the range of frequencies considered being central for cortical speech processing, might be influenced by the cerebellum. Generally speaking, higher-frequency cerebellar activity may interact with thetarange oscillations serving to implement a "temporal coding scheme," which allows fast processing and serves learningdependent timing in response to unexpected events and memory retrieval (deZeeuw et al., 2008). A similar type of interaction may be necessary to achieve the temporal resolution that ensures maximal temporal precision within the cerebellar temporal processing system, i.e. the precise sampling of the temporal locus of event rates in the theta range by oscillations operating at considerably higher frequencies (up to $260 \mathrm{~Hz}$; deZeeuw et al., 2008).

\section{Conclusions and future directions}

Taken together, we suggest that linking the proposed roles of the cerebellum in dedicated temporal processing and preparatory function on the basis of oscillatory activity is key to a better understanding of the cerebellar contributions to speech perception. However, next to the functions discussed so far, one of the most important questions concerns the role of the cerebellum in sensorimotor internal (forward) modeling (Ramnani, 2006; Wolpert, Miall, \& Kawato, 1998): We know that the cerebellum contributes 
(A) temporal processing

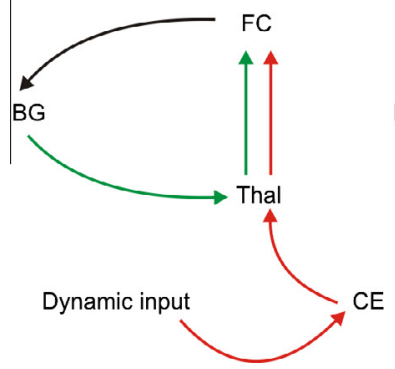

(B) temporal / speech processing

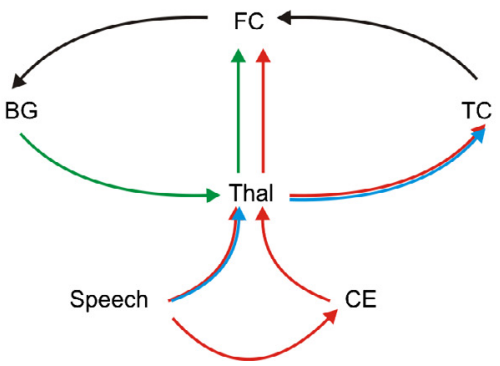

(C) oscillatory activity

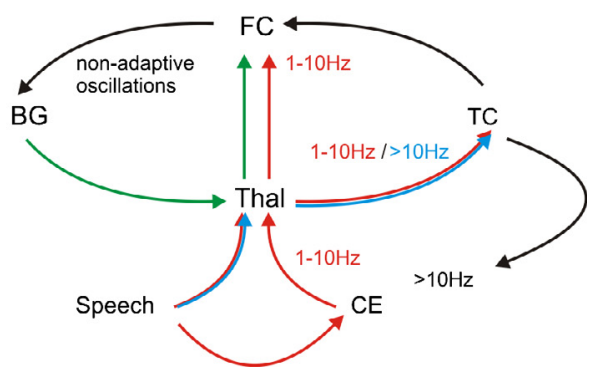

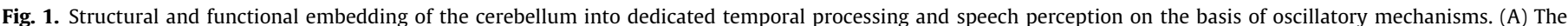

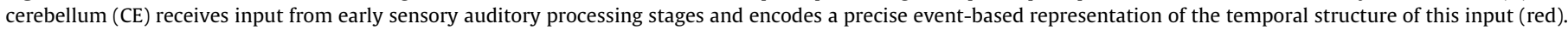

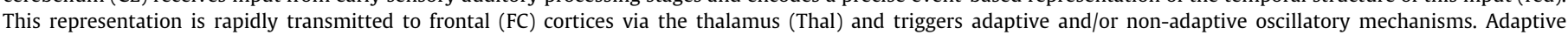

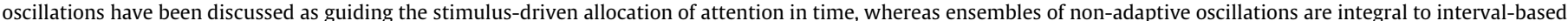

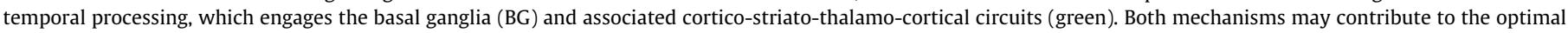

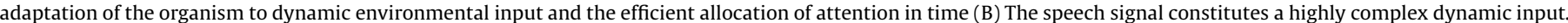

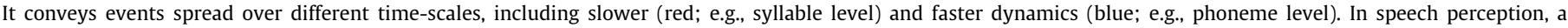

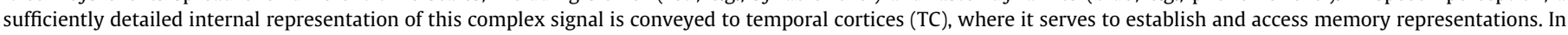

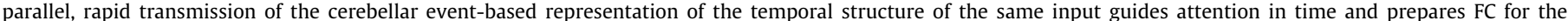

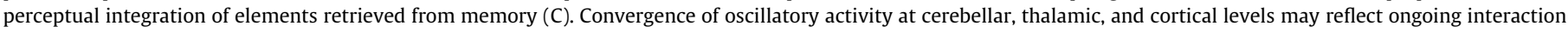

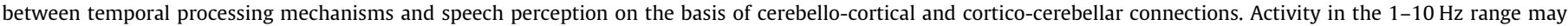

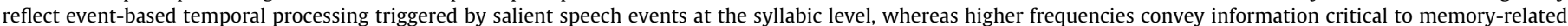

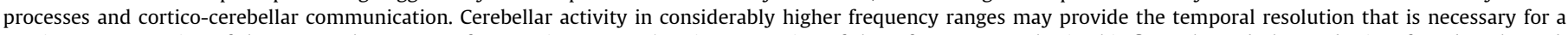

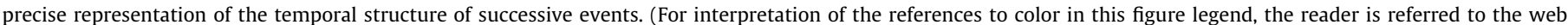
version of this article.)

Table 1

Proposed function of oscillatory activity in selected frequency ranges.

\begin{tabular}{|c|c|c|}
\hline Range & Location & Function \\
\hline $1-10 \mathrm{~Hz}$ & Cerebellum & Precise encoding of non-linear (event-based) stimulus representation \\
\hline $1-10 \mathrm{~Hz}(4 \mathrm{~Hz})$ & Thalamus/frontal cortex & Transmission and amplification of non-linear stimulus representation; "wake-up-call" \\
\hline $1-10 \mathrm{~Hz}$ & Temporal cortex & Tracking of syllable structure \\
\hline $1-10 \mathrm{~Hz}$ & Frontal cortex & Stimulus-driven attending; attention-dependent temporal processing \\
\hline$>25 \mathrm{~Hz}$ & Thalamus/temporal cortex & $\begin{array}{l}\text { Encoding of linear (continuous) stimulus representation; establishment of memory representations and memory } \\
\text { access }\end{array}$ \\
\hline$>25 \mathrm{~Hz}(40 \mathrm{~Hz})$ & $\begin{array}{l}\text { Cerebellum/temporal } \\
\text { cortex }\end{array}$ & Cortico-cerebellar communication; memory \\
\hline $\begin{array}{l}\text { High } \\
\text { frequency }\end{array}$ & Cerebellum & Temporal precision \\
\hline
\end{tabular}

to this type of modeling, but does it extend to sensory processing, and, consequently to speech perception? These domains may converge in aspects such as the detection of a discrepancy (error) between the modeled (predicted) and the actual sensory information, the adaptation to (learning) of new information, and in the updating of a generalized "mental model" of the environment (Kotz, Stockert, \& Schwartze, 2014). However, whether (i) these are genuine aspects of cerebellar function or (ii) they rely on the cerebello-cortical interplay, and (iii) they interact with dedicated temporal processing remains to be determined. Although the current proposal offers several potential venues for a functional and structural embedding of the cerebellum and cerebellar eventbased temporal processing into auditory processing in general and speech perception in particular, the current proposition serves as a starting point for further investigations exploring it.

\section{Acknowledgment}

This work is supported by DFG - Germany KO2268/6-1 granted to S. A. K.

\section{References}

Ackermann, H. (2008). Cerebellar contributions to speech production and speech perception: Psycholinguistic and neurobiological perspectives. Trends in Neurosciences, 31, 265-272.
Ackermann, H., \& Hertrich, I. (2000). The contribution of the cerebellum to speech processing. Journal of Neurolinguistics, 13, 95-116.

Ackermann, H., Mathiak, K., \& Riecker, A. (2007). The contribution of the cerebellum to speech production and speech perception: Clinical and functional imaging data. Cerebellum, 6, 202-213.

Ackermann, H., Riecker, A., Mathiak, K., Erb, M., Grodd, W., \& Wildgruber, D. (2001). Rate-dependent activation of a prefrontal-insular-cerebellar network during passive listening to trains of click stimuli: An fMRI study. Neuroreport, 12, 4087-4092.

Akkal, D., Dum, R. P., \& Stick, P. L. (2007). Supplementary motor area and presupplementary motor area: Targets of basal ganglia and cerebellar output. The Journal of Neuroscience, 27, 10659-10673.

Baumann, O., Borra, R. J., Bower, J. M., Cullen, K. E., Habas, C., Ivry, R. B., ... Sokolov, A A. (2014). Concensus paper: The role of the cerebellum in perceptual processes. Cerebellum. http://dx.doi.org/10.1007/s12311-014-0627-7.

Bernard, J. A., Peltier, S. J., Benson, B. L., Wiggins, J. L., Jaeggi, S. M., Buschkuehl, M., ... Seidler, R. D. (2013). Dissociable functional networks of the human dentate nucleus. Cerebral Cortex. http://dx.doi.org/10.1093/cercor/bht065.

Bostan, A. C., Dum, R. P., \& Strick, P. L. (2013). Cerebellar networks with the cerebral cortex and basal ganglia. Trends in Cognitive Sciences, 17, 241-254.

Buckner, R. L., Krienen, F. M., Castellanos, A., Diaz, J. C., \& Yeo, B. T. (2011). The organization of the human cerebellum estimated by intrinsic functional connectivity. Journal of Neurophysiology, 106, 2322-2345.

Buhusi, C. V., \& Meck, W. H. (2005). What makes us tick? Functional and neural mechanisms of interval timing. Nature Reviews Neuroscience, 6, 755-765.

Callan, D. E., Kawato, M., Parsons, L., \& Turner, R. (2007). Speech and song: The role of the cerebellum. Cerebellum, 6, 321-327.

Chen, C. H., Fremont, R., Arteaga-Bracho, E. E., \& Khodakhah, K. (2014). Short latency cerebellar modulation of the basal ganglia. Nature Neuroscience, 17, 1767-1777.

Chomsky, N. (1965). Aspects of the theory of syntax. Cambridge, Massachusetts: MIT Press.

Coull, J. T., Cheng, R., \& Meck, W. H. (2011). Neuroanatomical and neurochemical substrates of timing. Neuropsychopharmacology, 36, 1-25. 
Courchesne, E., \& Allen, G. (1997). Prediction and preparation, fundamental functions of the cerebellum. Learning and Memory, 4, 1-35.

D’Angelo, E., Koekkoek, S. K. E., Lombardo, P., Solinas, S., Ros, E., Garrido, J., ... De Zeeuw, C. I. (2009). Timing in the cerebellum: Oscillations and resonance in the granular layer. Neuroscience, 162, 805-815.

Dalal, S., Ospinova, D., Bertrand, O., \& Jerbi, K. (2013). Oscillatory activity of the human cerebellum: The intracranial electrocerebellogram revisited. Neuroscience and Biobehavioral Reviews, 37, 585-593.

deZeeuw, C. I., Hoebeek, F. E., \& Schonewille, M. (2008). Causes and consequences of oscillations in the cerebellar cortex. Neuron, 58, 655-658.

Friederici, A. D. (2009). Pathways to language: Fiber tracts in the human brain. Trends in Cognitive Sciences, 13, 175-181.

Fuster, J. M. (1995). Temporal processing. In J. Grafman, K. J. Holyoak, \& F. Boller (Eds.), Structure and function of the human prefrontal cortex (pp. 173-181). New York: N.Y. Academy of Sciences.

Ghitza, O. (2012). On the role of theta-driven syllabic parsing in decoding speech: Intelligibility of speech with a manipulated modulation spectrum. Frontiers in Psychology, 3, 238.

Ghitza, O. (2013). The theta-syllable: A unit of speech information defined by cortical function. Frontiers in Psychology, 4, 138.

Giraud, A., Kleinschmidt, A., Poeppel, D., Lund, T. E., Frackowiak, R. S. J., \& Laufs, H. (2007). Endogenous cortical rhythms determine cerebral specialization for speech perception and production. Neuron, 56, 1127-1134.

Greenberg, S., Carvey, H., Hitchcock, L., \& Chang, S. (2003). Temporal properties of spontaneous speech - Syllable-centric perspective. Journal of Phonetics, 31, 465-485.

Greenberg, S. (2006). A multi-tier framework for understanding spoken language. In S. Greenberg \& W. A. Ainsworth (Eds.), Listening to speech: An auditory perspective (pp. 411-434). Mahwah: Erlbaum.

Huang, C., Liu, G., \& Huang, R. (1982). Projections from the cochlear nucleus to the cerebellum. Brain Research, 244, 1-8.

Ivry, R. B. (1996). The representation of temporal information in perception and motor control. Current Opinion in Neurobiology, 6, 851-857.

Ivry, R. B., \& Schlerf, J. E. (2008). Dedicated and intrinsic models of time perception. Trends in Cognitive Sciences, 12, 273-280.

Kluender, K. R., Coady, J. A., \& Kiefte, M. (2003). Sensitivity to change in perception of speech. Speech Communication, 41, 59-69.

Kotz, S. A., Stockert, A., \& Schwartze, M. (2014). Cerebellum, temporal predictability and the updating of a mental model. Philosophical Transactions of the Royal Society B, 369, 20130403.

Kotz, S. A., \& Schwartze, M. (2010). Cortical speech processing unplugged: A timely subcortico-cortical framework. Trends in Cognitive Sciences, 14, 392-399.

Koziol, L. F., Budding, D., Andreasen, N., D’Arrigo, S., Bulgheroni, S., Imamizu, H., .. Yamazaki, T. (2014). Consensus paper: The cerebellum's role in movement and cognition. Cerebellum, 13, 151-177.

Large, E. W., \& Jones, M. R. (1999). The dynamics of attending: How people track time-varying events. Psychological Review, 106, 119-159.

Lockwood, A. H., Salvi, R. J., Coad, M. L., Arnold, S. A., Wack, D. S., Murphy, B. W., et al. (1999). The functional anatomy of the normal human auditory system: Responses to 0.5 and $4.0 \mathrm{kHz}$ tones at varied intensities. Cerebral Cortex, 9, 65-76.

Lorenzo, D., Velluti, J. C., Crispino, L., \& Velluti, R. (1977). Cerebellar sensory functions: Rat auditory evoked potentials. Experimental Neurology, 55, 629-636.

MacNeilage, P. F. \& Davis, B. L. (2001). Motor mechanisms in speech ontogeny: Phylogenetic, neurobiological and linguistic implications. Current Opinion in Neurobiology, 11, 696-700.
Manto, M., Bower, J. M., Conforto, A. B., Delgado-García, J. M., da Guarda, S. N., Gerwig, M., ... Timmann, D. (2012). Consensus paper: Roles of the cerebellum in motor control - The diversity of ideas on cerebellar involvement in movement. Cerebellum, 11, 457-487.

Mariën, P., Ackermann, H., Adamaszek, M., Barwood, C. H., Beaton, A., Desmond, J., ... Ziegler, W. (2014). Consensus paper: Language and the cerebellum: An ongoing enigma. Cerebellum, 13, 386-410.

Murdoch, B. E. (2010). The cerebellum and language: Historical perspective and review. Cortex, 46, 858-868.

Pastor, M. A., Vidaurre, C., Fernández-Seara, M. A., Villanueva, A., \& Friston, K. J (2008). Frequency-specific coupling in the cortico-cerebellar auditory system. Journal of Neurophysiology, 100, 1699-1705.

Pelle, J. E., \& Davis, M. H. (2012). Neural oscillations carry speech rhythm through to comprehension. Frontiers in Psychology, 3, 320.

Petacchi, A., Laird, A. R., Fox, P. T., \& Bower, J. M. (2005). Cerebellum and auditory function: An ALE meta-analysis of functional neuroimaging studies. Human Brain Mapping, 25, 118-128.

Ramnani, N. (2006). The primate cortico-cerebellar system: Anatomy and function Nature Reviews Neuroscience, 7, 511-522.

Rilling, J. K., Glasser, M. F., Preuss, T. M., Ma, X., Zhao, T., Hu, X., et al. (2008). The evolution of the arcuate fasciculus revealed with comparative DTI. Nature Neuroscience, 11, 426-428.

Rosen, S. (1992). Temporal information in speech: Acoustic, auditory and linguistic aspects. Philosophical Transactions of the Royal Society B, 336, 367-373.

Schwartze, M., \& Kotz, S. A. (2013). A dual-pathway neural architecture for specific temporal prediction. Neuroscience and Biobehavioral Reviews, 37, 2587-2596.

Schwartze, M., Tavano, A., Schröger, E., \& Kotz, S. A. (2012). Temporal aspects of prediction in audition: Cortical and subcortical neural mechanisms. International Journal of Psychophysiology, 83, 200-207.

Shamma, S. (2003). Physiological foundations of temporal integration in the perception of speech. Journal of Phonetics, 31, 495-501.

Sherman, S. M. (2001). A wake-up call from the thalamus. Nature Neuroscience, 4 , 344-346.

Sherman, S. M., \& Guillery, R. W. (2006). Exploring the role of the thalamus and its role in cortical function. Cambridge: MIT Press.

Solinas, S., Forti, L., Cesana, E., Mapelli, J., De Schutter, E., \& D’Angelo, E. (2007). Fastreset of pacemaking and theta-frequency resonance patterns in cerebellar Golgi cells: Simulations of their impact in vivo. Frontiers in Cellular Neuroscience, 1, 4

Spencer, R. M. C., \& Ivry, R. B. (2013). Cerebellum and timing. In M. Manto, D. L. Grual, J. D. Schmahmann, N. Koibuchi, \& F. Rossi (Eds.), Handbook of the cerebellum and cerebellar disorders (pp. 1201-1219). Dondrecht: Springer.

Spencer, R. M. C., Zelaznik, H. N., Diedrichsen, J., \& Ivry, R. B. (2003). Disrupted timing of discontinuous but not continuous movements by cerebellar lesions. Science, 300, 1437-1439.

Strick, P. L., Dum, R. P., \& Fiez, J. A. (2009). Cerebellum and nonmotor function. Annual Review of Neuroscience, 32, 413-434.

Watson, T. C., Becker, N., Apps, R., \& Jones, M. W. (2014). Back to front: Cerebellar connections and interactions with the prefrontal cortex. Frontiers in Systems Neuroscience, 8, 4.

Wiener, M., Turkeltaub, P., \& Coslett, H. B. (2010). The image of time: A voxel-wise meta-analysis. Neuroimage, 49, 1728-1740.

Wolpert, D. M., Miall, R. C., \& Kawato, M. (1998). Internal models in the cerebellum. Trends in Cognitive Sciences, 2, 338-347. 